\title{
Launching Evolutionary Psychological Science
}

\author{
Todd K. Shackelford
}

Published online: 27 November 2014

(C) Springer International Publishing 2014

Darwin's (1859) theory of evolution by natural selection revolutionized our understanding of life, revealing the natural, gradual, blind process that built biological features once assumed to be intelligently designed. In addition to providing a natural account of complex adaptations, Darwin's theory illustrates that the stupendous biological diversity we see today, from minks and manatees to daffodils and gonorrhea, can be traced to a common ancestor. Although Darwin (1859) mostly avoided the topic in the Origin of Species, it was clear then that his theory had profound implications for the origin of humans. It is now recognized that humans are but one branch on the Tree of Life, that we have existed in anatomically modern form for 200,000 years (McDougall et al. 2005) and that our closest living relative is the chimpanzee, with whom we share a common ancestor dating back 6-7 million years (Zimmer 2006).

Despite the acceptance in the scientific community of the fact of human evolution, the social and behavioral sciences have historically ignored this reality, resulting in theoretical assumptions and empirical research that have not been informed by an evolutionary perspective. This is especially evident with regard to the Standard Social Science Model (Tooby and Cosmides 1992), a predominant view of the mind as a "blank slate" comprising a few content-independent learning and reasoning mechanisms (Pinker 2002; Tooby and Cosmides 1992, 2005). Evolutionary psychology has ushered in a paradigm shift in which the mind is understood as a product of specific and recurrent selection pressures acting over deep evolutionary time.

The social and behavioral sciences have long been dominated by theories that do not account for human evolutionary history (Tooby and Cosmides 2005). Psychologists often

T. K. Shackelford $(\bowtie)$

Department of Psychology, Oakland University, Rochester, MI, USA e-mail: shackelf@oakland.edu focus on the immediate causes of a particular phenomenon; that is, they rely on proximate explanations (Liddle, Bush, \& Shackelford, 2011). Although proximate causes are pieces of the puzzle of human nature, it is necessary to identify the ultimate causes to understand why particular psychological phenomena occur in the first place. Evolutionary psychology represents a rigorous scholarly effort to identify these ultimate causes by explicit recourse to natural selection as a foundation for generating hypotheses about human nature (Buss 2012; Tinbergen 1963).

Evolutionary psychology is based on the premise that the brain, like all other organs, includes information-processing adaptations built by natural selection over human evolutionary history (along with adaptations inherited from ancestral species that existed before humans). Evolutionary psychologists argue that the brain is not a domain-general problem-solving device. When one considers any other organ, such as the heart, it is clear that it embodies evolved solutions to specific adaptive problems. Given the variety of functions performed by the brain and the fact that adaptations are produced by recurrent and specific problems of survival and reproduction, evolutionary psychology posits that our brain includes a multitude of domain-specific adaptations, each of which solves a unique adaptive problem (Buss 2012).

Evolutionary psychology is best viewed as an approach to the social and behavioral sciences. Evolutionary psychologists are not limited to investigating particular topics such as social behavior, cognitive development, or personality; an evolutionary perspective can be applied to any area of the social and behavioral sciences and other scholarly pursuits besides. Evolutionary psychology is uniquely suited to provide a unifying framework for the currently disparate subdisciplines of psychology, and indeed for the social and behavioral sciences, broadly considered. The current division of areas of psychological study appears unnatural and arbitrary when one adopts an evolutionary perspective. Buss (2005, pp. xxiv-xxv) illustrates this in a discussion of stranger anxiety: 
In which subdiscipline of psychology does stranger anxiety belong? It obviously involves information processing and this could be claimed by cognitive psychology. It shows a predictable ontogenetic unfolding, so it could be claimed by developmental psychology. It is activated by interactions with others, so it belongs to social psychology. Individual infants differ in the intensity of stranger anxiety, so it falls within the province of personality psychology. The mechanism can malfunction in a minority of infants, so it's relevant to clinical psychology. And its biological substrate must include the brain, so neuroscience can also lay claim. Obviously, stranger anxiety belongs simultaneously to all or to none.

An evolutionary perspective provides a nonarbitrary means of carving up psychological science by focusing attention on the different categories of adaptive problems faced by humans (Buss 2003). Evolutionary psychologists have generated and tested hypotheses related to an impressive variety of specific adaptive problems, such as problems associated with parenting [e.g., the problems of paternity uncertainty and motheroffspring conflict in utero (Haig 1993) and parent-offspring conflict over mating (Apostolou 2007)], kinship [e.g., the problems of kin recognition (Weisfeld et al. 2003; Lieberman et al. 2007), incest avoidance (Weisfeld et al. 2003; Lieberman et al. 2007), and grandparental investment (Euler and Weitzel 1996)], and group living [e.g., the problems of promoting cooperation and thwarting free-riding (Trivers 1971; Cosmides and Tooby 1992)].

Despite the voluminous theoretical and empirical literature generated by evolutionary psychologists in recent years, evolutionary psychology is a young field and there remain many exciting areas for research. For example, evolutionary psychologists have historically not focused significant attention on individual differences, focusing instead on species-typical or sex-typical adaptations. This trend has shifted in recent years, particularly with the advancement of evolutionary personality psychology (e.g., Figueredo et al. 2005), but researchers are still in the early stages of testing hypotheses generated in this area. Related topics that will benefit from increased empirical attention include culture and cultural differences (Buss 2012). Although the literature on the evolution of religious beliefs and behaviors has expanded rapidly in recent years (Atran 2002; Boyer 2001; Wright 2009; Kirkpatrick 2008), there remains considerable debate as to whether religion is best viewed as an adaptation, a byproduct of one or more adaptations that evolved to solve different adaptive problems, or perhaps some combination of these perspectives. Other areas that historically have received more attention from evolutionary psychologists, such as mating psychology, still harbor many questions and debated issues. Some examples include whether female orgasm is an adaptation or a byproduct of other adaptations (Kaighobadi et al. 2012), the evolution of concealed ovulation and whether men have adaptations for detecting ovulation (Buss 2012; Symons 1995), and the evolution of homosexuality (Buss 2012). The rich behavioral repertoire and complex cognitive architecture of humans ensure that an evolutionary perspective still has much to reveal about human and nonhuman natures. I am therefore thrilled to announce the launching of Evolutionary Psychological Science.

Evolutionary Psychological Science is an international, interdisciplinary journal that publishes empirical research, theoretical contributions, literature reviews, and commentaries addressing human evolved psychology and behavior. The Journal especially welcomes submissions on nonhumans that inform human psychology and behavior, as well as submissions that address clinical implications and applications of an evolutionary perspective. The Journal is informed by all the social and life sciences, including anthropology, biology, criminology, law, medicine, philosophy, political science, and the humanities and welcomes contributions from these and related fields that contribute to the understanding of human evolved psychology and behavior.

\section{References}

Apostolou, M. (2007). Sexual selection under parental choice: the role of parents in the evolution of human mating. Evolutionary and Human Behavior, 28, 403-409.

Atran, S. (2002). In gods we trust: the evolutionary landscape of religion. New York: Oxford University Press.

Boyer, P. (2001). Religion explained: the evolutionary origins of religious thought. New York: Basic Books.

Buss, D. M. (2003). The evolution of desire: strategies of human mating, revised ed. New York: Free Press.

Buss, D. M. (2005). Introduction: the emergence of evolutionary psychology. In D. M. Buss (Ed.), The handbook of evolutionary psychology (pp. xxiii-xxv). Hoboken: Wiley.

Buss, D.M. (2012). Evolutionary psychology: The New science of the mind (4th ed.). Boston: Allyn \& Bacon.

Cosmides, L., \& Tooby, J. (1992). Cognitive adaptations for social exchange. In J. Barkow, L. Cosmides, \& J. Tooby (Eds.), The adapted mind: evolutionary psychology and the generation of culture (pp. 163-228). New York: Oxford University Press.

Darwin, C. (1859). On the origin of species by means of natural selection. London: John Murray.

Euler, H. A., \& Weitzel, B. (1996). Discriminative grandparental solicitude as reproductive strategy. Human Nature, 7, 39-59.

Figueredo, A. J., Sefcek, J. A., Vasquez, G., Brumbach, B. H., King, J. E., \& Jacobs, W. J. (2005). Evolutionary personality psychology. In D. M. Buss (Ed.), The handbook of evolutionary psychology (pp. 851877). Hoboken: Wiley.

Haig, D. (1993). Genetic conflicts in human pregnancy. The Quarterly Review of Biology, 68, 495-532.

Kaighobadi, F., Shackelford, T. K., \& Weekes-Shackelford, V. A. (2012). Do women pretend orgasm to retain a mate? Archives of Sexual Behavior, 41, 1121-1125.

Kirkpatrick, L. A. (2008). Religion is not an adaptation: some fundamental issues and arguments. In J. Bulbulia, R. Sosis, E. Harris, R. Genet, C. 
Genet, \& K. Wyman (Eds.), The evolution of religion: studies, theories, and critiques (pp. 61-66). Santa Margarita: Collins Foundation Press.

Liddle, J.R., Bush, L.S., \& Shackelford, T.K. (2011). An introduction to evolutionary psychology and its application to suicide terrorism. Behavioral Sciences of Terrorism and Political Aggression, 3, 176197.

Lieberman, D., Tooby, J., \& Cosmides, L. (2007). The architecture of human kin detection. Nature, 445, 727-731.

McDougall, I., Brown, F. H., \& Fleagle, J. G. (2005). Stratigraphic placement and age of modern humans from Kibish, Ethiopia. Nature, 433, 733-736.

Pinker, S. (2002). The blank slate. New York: Viking.

Symons, D. (1995). Beauty is in the adaptations of the beholder: the evolutionary psychology of human female sexual attractiveness. In P. R. Abramson \& S. D. Pinkerton (Eds.), Sexual nature, sexual culture (pp. 80-118). Chicago: University of Chicago Press.

Tinbergen, N. (1963). On aims and methods of ethology. Zeitschrift für Tierpsychologie, 20, 410-433.
Tooby, J., \& Cosmides, L. (1992). The psychological foundations of culture. In J. Barkow, L. Cosmides, \& J. Tooby (Eds.), The adapted mind: evolutionary psychology and the generation of culture (pp. 19136). New York: Oxford University Press.

Tooby, J., \& Cosmides, L. (2005). Conceptual foundations of evolutionary psychology. In D. M. Buss (Ed.), The handbook of evolutionary psychology (pp. 5-67). Hoboken: Wiley.

Trivers, R. (1971). The evolution of reciprocal altruism. Quarterly Review of Biology, 46, 35-57.

Weisfeld, G. E., Czili, T., Phillips, K. A., Gall, J. A., \& Lichtman, C. M. (2003). Possible olfaction-based mechanisms in human kin recognition and inbreeding avoidance. Journal of Experimental Child Psychology, 85, 279-295.

Wright, R. (2009). The evolution of God. New York: Little, Brown and Company.

Zimmer, C. (2006). Evolution: the triumph of an idea. New York: Harper Perennial. 